\title{
Mechanistic study of the cause of decreased blood 1,25-Dihydroxyvitamin D in sepsis
}

Chih-Huang $\mathrm{Li}^{1,2,3+}$, Xiaolei Tang ${ }^{1,4^{*+}} \mathbb{D}$, Samiksha Wasnik', Xiaohua Wang ${ }^{1,5}$, Jintao Zhang ${ }^{1,6}, Y_{i} X^{1}{ }^{1}$, Kin-Hing William Lau ${ }^{1,7}$, H. Bryant Nguyen ${ }^{1,8}$ and David J. Baylink ${ }^{1}$

\begin{abstract}
Background: Vitamin D deficiency, determined by blood levels of 25-hydroxyvitamin D [25(OH) D, i.e. the major vitamin $\mathrm{D}$ form in blood], has been shown to associate with all-cause mortalities. We recently demonstrated that blood levels of 1,25-dihydroxyvitamin $\mathrm{D}\left[1,25(\mathrm{OH})_{2} \mathrm{D}\right.$, i.e. the active vitamin $\left.\mathrm{D}\right]$ were significantly lower in nonsurvivors compared to survivors among sepsis patients. Unexpectedly, despite the well documented roles of 1 , $25(\mathrm{OH})_{2} \mathrm{D}$ in multiple biological functions such as regulation of immune responses, stimulation of antimicrobials, and maintenance of barrier function, $1,25(\mathrm{OH})_{2} \mathrm{D}$ supplementation failed to improve disease outcomes. These previous findings suggest that, in addition to $1,25(\mathrm{OH})_{2} \mathrm{D}$ deficiency, disorders leading to the $1,25(\mathrm{OH})_{2} \mathrm{D}$ deficiency also contribute to mortality among sepsis patients. Therefore, this study investigated the mechanisms leading to sepsis-associated 1,25(OH) 2 D deficiency.
\end{abstract}

Methods: We studied mechanisms known to regulate kidney 25-hydroxylvitamin D 1a-hydroxylase which physiologically catalyzes the conversion of $25(\mathrm{OH}) \mathrm{D}$ into $1,25(\mathrm{OH})_{2} \mathrm{D}$. Such mechanisms included parathyroid hormone (PTH), insulin-like growth factor 1 (IGF-1), fibroblast growth factor 23 (FGF-23), and kidney function.

Results: We demonstrated in both human subjects and mice that sepsis-associated $1,25(\mathrm{OH})_{2} \mathrm{D}$ deficiency could not be overcome by increased production of PTH which stimulates 1a-hydroxylase. Further studies showed that this failure of PTH to maintain blood $1,25(\mathrm{OH})_{2}$ D levels was associated with decreased blood levels of IGF-1, increased blood levels of FGF-23, and kidney failure. Since the increase in blood levels of FGF-23 is known to associate with kidney failure, we further investigated the mechanisms leading to sepsis-induced decrease in blood levels of IGF-1. Our data showed that blood levels of growth hormone, which stimulates IGF-1 production in liver, were increased but could not overcome the IGF-1 deficiency. Additionally, we found that the inability of growth hormone to restore the IGF-1 deficiency was associated with suppressed expression and signaling of growth hormone receptor in liver.

Conclusions: Because FGF-23 and IGF-1 have multiple biological functions besides their role in regulating kidney 1a-hydroxylase, our data suggest that FGF-23 and IGF-1 are warranted for further investigation as potential agents for the correction of $1,25(\mathrm{OH})_{2} \mathrm{D}$ deficiency and for the improvement of survival among sepsis patients.

Keywords: Sepsis, 1,25-dihydroxyvitamin D, 25-hydroxyvitamin D 1a-hydroxylase, Insulin-like growth factor 1, Fibroblast growth factor 23, Parathyroid hormone

\footnotetext{
* Correspondence: xitang@llu.edu; Xiaolei.tang@liu.edu

${ }^{+}$Chih-Huang Li and Xiaolei Tang contributed equally to this work.

${ }^{1}$ Department of Medicine, Division of Regenerative Medicine, Loma Linda

University, Loma Linda, California, USA

${ }^{4}$ Department of Veterinary Biomedical Sciences, College of Veterinary

Medicine, Long Island University, Brookville, NY 11548, USA

Full list of author information is available at the end of the article
}

(c) The Author(s). 2019 Open Access This article is distributed under the terms of the Creative Commons Attribution 4.0 International License (http://creativecommons.org/licenses/by/4.0/), which permits unrestricted use, distribution, and reproduction in any medium, provided you give appropriate credit to the original author(s) and the source, provide a link to the Creative Commons license, and indicate if changes were made. The Creative Commons Public Domain Dedication waiver (http://creativecommons.org/publicdomain/zero/1.0/) applies to the data made available in this article, unless otherwise stated. 


\section{Background}

In the past decade, there was a rejuvenation of interest in the relationship between vitamin D and infection [1]. As a result, an appreciable amount of data have accumulated to support that vitamin D deficiency as determined by blood 25-hydroxyvitamin D $(25[\mathrm{OH}] \mathrm{D})$ levels is associated with all-cause mortalities [2-6]. In our previous studies, we uncovered that blood levels of 1,25-dihydroxyvitamin D (or 1, $25[\mathrm{OH}]_{2} \mathrm{D}$, i.e. the active vitamin $\mathrm{D}$ metabolite) were significantly lower in non-survivor sepsis patients when compared to survivor sepsis patients and hence an independent predictor of sepsis mortality [7]. Our discoveries are consistent with a finding from another laboratory showing that low blood levels of 1 , $25(\mathrm{OH})_{2} \mathrm{D}$ during hospital admission are associated with sequential organ failure (SOFA) in critically ill patients [8].

These previous findings on the association of 1 , $25(\mathrm{OH})_{2} \mathrm{D}$ deficiency with sepsis mortality are in agreement with recent discoveries that $1,25(\mathrm{OH})_{2} \mathrm{D}$ is important for maintaining the normal biological functions which are severely perturbed in sepsis patients [9-13]. These exciting discoveries have led to a growing interest in evaluating the potential of vitamin $\mathrm{D}$ supplementation for the treatment of sepsis. Accordingly, several clinical trials have been conducted to determine the effects of supplementation of native vitamin $\mathrm{D}$ or $1,25(\mathrm{OH})_{2} \mathrm{D}$ on disease outcome. However, so far there is no evidence to support that supplementation of native vitamin $\mathrm{D}$ can improve disease outcome [14]. Additionally, a clinical trial was conducted to evaluate a single intravenous dose of $1,25(\mathrm{OH})_{2} \mathrm{D}(2 \mu \mathrm{g})$ in patients with severe sepsis or septic shock [15]. The data showed that the $1,25(\mathrm{OH})_{2} \mathrm{D}$ supplementation, when compared to placebo control, increased leukocyte mRNA expressions of cathelicidin and interleukin-10 $24 \mathrm{~h}$ after the treatments. No other significant changes were observed, such as blood cytokine levels (interleukin-10 [IL-10], interleukin-6 [IL-6], tumor necrosis factor- $\alpha$ [TNF- $\alpha]$, interleukin-1 $\beta$ [IL-1 $\beta]$, and interleukin-2 [IL-2]), urinary kidney injury markers, and clinical outcomes. These negative data coupled with the known immune regulatory and antimicrobial functions of $1,25(\mathrm{OH})_{2} \mathrm{D}$ raise the possibility that the disorders leading to the $1,25(\mathrm{OH})_{2} \mathrm{D}$ deficiency also contribute to mortality among sepsis patients.

Accordingly, using blood samples of the same sepsis patient cohort from our previous study [7] and animals induced for sepsis, this study investigated the mechanisms underlying the sepsis-associated $1,25(\mathrm{OH})_{2} \mathrm{D}$ deficiency. We reasoned that such study should identify the mechanisms that can be potentially targeted for the correction of $1,25(\mathrm{OH})_{2} \mathrm{D}$ deficiency and for the improvement of survival among sepsis patients.

\section{Methods}

\section{Study participants}

Sepsis patient samples were the stored plasma samples from subjects previously enrolled at our multi-center observational study from January 2005 through June 2006 [16]. In addition, 20 de-identified age- and gendermatched healthy control blood samples were obtained from BioreclamationIVT (New York, USA). The healthy donors had no significant kidney, liver, or cardiovascular diseases. Study participants were enrolled with written informed consent. This human study was approved by the Loma Linda University Institutional Review Board for Human Research (IRB).

\section{Animals}

Six to eight weeks old C57BL/6 mice were used in this study and were purchased from the Jackson Laboratory. The animal study was approved by Loma Linda Institutional Animal Care and Use Committee (IACUC).

\section{Method of anesthesia}

Animals were anesthetized if necessary by isoflurane inhalation at $3.5-4.5 \%$ during induction phase and at $3 \%$ during maintenance phase.

\section{Method of euthanasia}

At the end of experiments, mice were euthanized in a high $\mathrm{CO}_{2}$ environment inside a sealed container that allowed for the mice to be observed during euthanasia. The number of mice euthanized at one time did not exceed the recommended number for the size of the container. Additionally, cervical dislocation was used as the second method to ensure that the animals did not revive. This method was consistent with the recommendations of the Panel on Euthanasia of the American Veterinary Medical Association.

\section{Mouse sepsis model}

Sepsis was induced in C57BL/6 mice with the cecal ligation and puncture approach, as previously described $[17,18]$. Livers and kidneys were harvested at euthanasia for RNA isolation. Animal studies were approved by the Loma Linda University Institutional Animal Care and Use Committee.

\section{Measurement of human biomarkers}

Human blood samples were stored at $-80{ }^{\circ} \mathrm{C}$ until assay without any freeze and thaw cycle. $1,25(\mathrm{OH})_{2} \mathrm{D}$ concentration was determined with a radioimmunoassay by the Heartland Assay Laboratory (Ames, Iowa). Calcium colorimetric was purchased from BioVision Inc. (Milpitas, CA, USA). Intact PTH was measured at the Loma Linda Medical Center as part of routine laboratory tests. Growth hormone $(\mathrm{GH})$ and IGF-1 were examined by 
enzyme-linked immunoassay (ELISA) using respective commercial kits purchased from R\&D Systems (Minneapolis, MN). Creatinine was measured by ELISA using a commercial kit from either Cayman Chemical (Ann Arbor, MI) or R\&D Systems (Minneapolis, MN).

\section{Measurement of murine biomarkers}

Mouse PTH ELISA kit and cyclic AMP ELISA kit were purchased from LifeSpan BioSciences (Seattle, WA) and Enzo Lifesciences (Farmingdale, NY), respectively. Calcium colorimetric was purchased from BioVision Inc. (Milpitas, CA, USA). IL-6 was determined using a mouse cytometric bead array kit (BD Biosciences, San Diego). GH and IGF-1 ELISA kits were purchased from R\&D Systems $^{\odot}$ (Minneapolis, MN, USA). $1,25(\mathrm{OH})_{2}$ D EIA kit was purchased from immunodiagnostic systems ${ }^{\bullet}$ (Fountain Hills, AZ, USA). Creatinine was examined by ELISA using a commercial kit from R\&D Systems (Minneapolis, $\mathrm{MN}$ ). All assays were performed according to the manufacturer's instructions. All experiments were performed using 5 mice per group with duplicates.

\section{RNA isolation and real-time polymerase chain reaction} Total RNA was isolated using an RNeasy Micro Kit ${ }^{\circ}$ (Qiagen, Valencia, CA) according to the manufacturer's instructions. First strand cDNA synthesis was performed using the SuperScript ${ }^{\circ}$ III Reverse Transcriptase (Life Technologies, Grand Island, NY). Quantities of specific mRNAs were determined by real-time PCR and normalized against the house-keeping gene, GAPDH mRNA, using specific primers. A list of primers used in this study is shown in Table 1.

\section{Statistical analysis}

Data were presented as mean \pm standard deviation. Shapiro-Wilks test was used to test the normality. t-test or Mann-Whitney $U$ test was used to test the difference of continuous variables. Fisher's exact test was used for the analysis of binomial variables. The two-tailed test was used for all variables. Correlation between continuous variables was performed using Spearman correlation analysis. $P<0.05$ was considered statistically significant.
All the statistical analyses were performed using GraphPad Prism ${ }^{\circ}$ (GraphPad, San Diego, CA, USA) or SPSS Statistics 22.

\section{Results}

Sepsis patients in general displayed suppressed blood $1,25(\mathrm{OH})_{2} \mathrm{D}$ levels which were associated with disorders of the mechanisms that regulate 25 -hydroxyvitamin $D$ 1ahydroxylase

In this current study, we obtained blood samples from healthy control subjects to compare with the total population of sepsis patients (survivors and non-survivors). Table 2 shows baseline characteristics of 20 healthy control subjects and 79 sepsis patients. Age and gender were similar between the two groups. However, ethnicity varied. Mortality of the sepsis patients was $11.4 \%$.

Our data showed that sepsis patients, when compared to healthy control subjects, had significantly increased blood levels of IL-6 (Fig. 1a and Additional file 1: Table S1, $184.2 \pm$ 25.8 vs. $6.2 \pm 3.4 \mathrm{ng} / \mathrm{mL}, p<0.001$ ), a data that supports ongoing inflammation in the sepsis patients. A previous report showed that critical ill patients, when compared to healthy control subjects, had significantly lower blood levels of 1 , $25(\mathrm{OH})_{2} \mathrm{D}$ [19]. Consistent with this previous finding, blood $1,25(\mathrm{OH})_{2} \mathrm{D}$ levels in our sepsis patients, when compared to healthy control subjects, were significantly decreased (Fig. 1b and Additional file 1: Table S1, $28.8 \pm 1.5$ vs. $83.1 \pm 6.4 \mathrm{pmol} /$ $\mathrm{L}, p<0.001)$. This decreased blood $1,25(\mathrm{OH})_{2} \mathrm{D}$ levels in sepsis patients were consistent with significantly decreased blood calcium levels (Fig. 1c and Additional file 1: Table S1, $8.9 \pm$ 0.2 vs. $9.7 \pm 0.1 \mathrm{mg} / \mathrm{dL}, \mathrm{p}<0.001)$. Collectively, data from our studies and others have demonstrated that $1,25(\mathrm{OH})_{2} \mathrm{D}$ deficiency is present in all sepsis patients.

Because the major source of blood $1,25(\mathrm{OH})_{2} \mathrm{D}$ is kidney where $1,25(\mathrm{OH})_{2} \mathrm{D}$ is converted from 25 -hydroxyvitamin $\mathrm{D}$ $[25(\mathrm{OH}) \mathrm{D}]$ by $1 \alpha$-hydroxylase $[25(\mathrm{OH}) \mathrm{D}$ is the major vitamin D form in blood] [20], we further evaluated the mechanisms that regulate kidney $1 \alpha$-hydroxylase. Our data showed that, when compared to healthy control subjects, sepsis patients displayed markedly higher blood levels of PTH (Fig. 1d and Additional file 1: Table S1, $68.2 \pm 7.7$ vs. $10.6 \pm 1.7 \mathrm{pmol} / \mathrm{L}, \mathrm{p}<0.001$ ), FGF-23 (Fig. 1e and Additional

Table 1 PCR Primers Used in this Study

\begin{tabular}{lll}
\hline Genes & Forward primers & Reverse primers \\
\hline GHR & 5'-AGGTCTCAGGTATGGATCTTTGTCA-3' & 5'-GCCAAGAGTAGCTGGTGTAGCCT-3' \\
IGF-1 & 5'-GCTTGCTCACCTTCACCAGC-3' & 5'-AATGTACTTCCTTCTGAGTCT-3' \\
IGFBP3 & 5'-GACGACGTACATTGCCTCAG-3' & 5'-GTCTTTTGTGCAAAATAAGGCATA-3' \\
Socs3 & 5'-GCTCCAAAAGCGAGTACCAGC-3' & 5'-AGTAGAATCCGCTCTCCTGCAG-3' $^{\prime}$ \\
CYP27B1 & 5'-ACCCGACACGGAGACCTTC-3' & 5'-ATGGTCAACAGCGTGGACAC-3' \\
GAPDH & 5'-AATCCCATCACCATCTTCCA-3' & 5'-TGGACTCCACGACGTACTCA-3' \\
\hline
\end{tabular}


Table 2 Characteristics of Sepsis Patients and Health Controls

\begin{tabular}{|c|c|c|c|}
\hline \multicolumn{2}{|l|}{ Categories } & \multirow{2}{*}{$\begin{array}{l}\text { Health Controls } \\
(n=20) \\
61.8 \pm 3.7\end{array}$} & \multirow{2}{*}{$\begin{array}{l}\text { Sepsis Patients } \\
(n=79)\end{array}$} \\
\hline Age, years & & & \\
\hline Male: Fema & & $9: 11$ & $38: 41$ \\
\hline \multirow[t]{4}{*}{ Ethnicity } & Caucasian, n(\%) & $6(30)$ & $50(63.3)$ \\
\hline & Hispanic, n(\%) & $7(35)$ & $14(17.7)$ \\
\hline & Asian, n(\%) & $0(0)$ & $10(12.7)$ \\
\hline & Black, n(\%) & $7(35)$ & $5(6.3)$ \\
\hline \multicolumn{4}{|c|}{ Comorbidities } \\
\hline \multicolumn{2}{|c|}{ None, n(\%) } & $20(100)$ & $18(22.8)$ \\
\hline \multicolumn{2}{|c|}{ Cardiovascular, n(\%) } & $0(0)$ & $32(40.5)$ \\
\hline \multicolumn{2}{|c|}{ Respiratory, n(\%) } & $0(0)$ & $23(29.1)$ \\
\hline \multicolumn{2}{|c|}{ Diabetes, n(\%) } & $0(0)$ & $16(20.3)$ \\
\hline \multicolumn{2}{|c|}{ Chronic kidney disease, n(\%) } & $0(0)$ & $6(7.6)$ \\
\hline \multicolumn{4}{|c|}{ Infection focus } \\
\hline \multicolumn{2}{|c|}{ Respiratory tract infection, n(\%) } & N/A & $28(35.4)$ \\
\hline \multicolumn{2}{|c|}{ Urinary tract infection, n(\%) } & N/A & $26(32.9)$ \\
\hline \multicolumn{2}{|c|}{ Intra-abdominal infection, n(\%) } & N/A & $14(17.7)$ \\
\hline \multicolumn{2}{|l|}{ Others } & N/A & $11(13.9)$ \\
\hline \multicolumn{2}{|c|}{ Acute Physiology and Chronic Health Evaluation II } & N/A & $13.5 \pm 3.7$ \\
\hline \multicolumn{2}{|c|}{ 30-day mortality, n(\%) } & N/A & $9(11.4)$ \\
\hline
\end{tabular}

A.

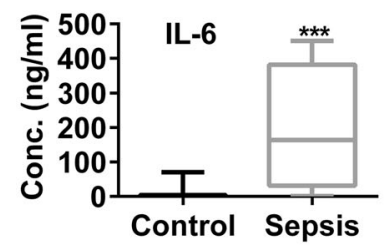

D.

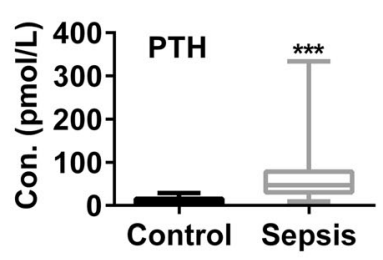

G.

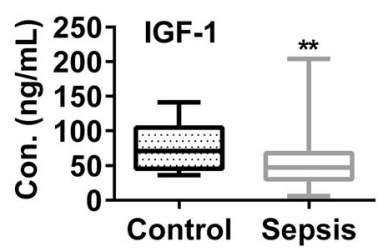

B.

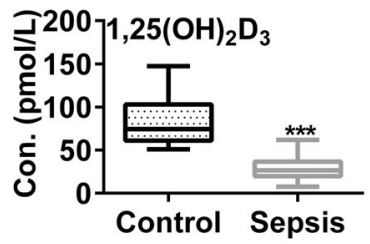

E.

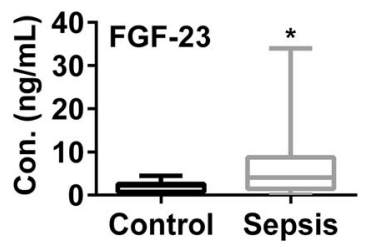

$\mathrm{H}$.

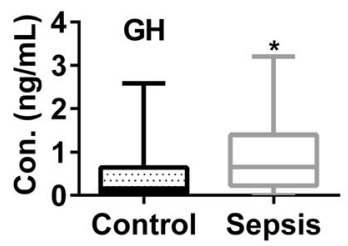

\section{C.}

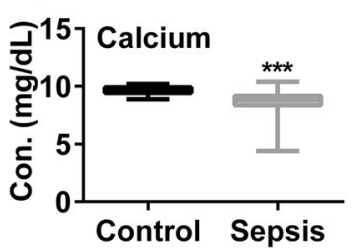

F.

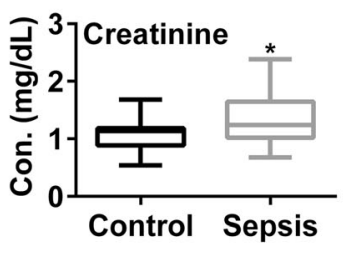

Fig. 1 Sepsis patients in general displayed suppressed blood 1,25(OH) 2 D levels which were associated with disorders of the mechanisms that regulate 1a-hydroxylase. Blood samples from 20 age- and gender-matched healthy subjects and 79 sepsis patients were examined for the concentrations of IL-6 (a), 1,25(OH) $2 \mathrm{D}(\mathbf{b})$, calcium $(\mathbf{c})$, PTH (d), FGF-23 (e), Creatinine (f), IGF-1 (g), and GH (h). Except for the calcium that was measured by colorimetric assay, other molecules were measured by ELISA. ${ }^{*} P<0.05$. ${ }^{* *} P<0.01$, ${ }^{* * *} P<0.001$. t-test or Mann-Whitney $U$ test 
file 1: Table S1, $7.3 \pm 2.0$ vs. $1.9 \pm 0.4 \mathrm{ng} / \mathrm{mL}, p<0.05$ ), and creatinine (Fig. If and Additional file 1: Table S1, $1.5 \pm 0.2$ vs. $1.0 \pm 0.1, \mathrm{p}<0.05)$, whereas showed significantly decreased blood levels of IGF-1 (Fig. 1g, $55.0 \pm 3.7$ vs. $77.3 \pm$ $7.4 \mathrm{ng} / \mathrm{mL}, p<0.01$ ). To support the decreased blood levels of IGF-1 during sepsis, sepsis patients, when compared to healthy control subjects, displayed significantly increased blood levels of growth hormone (GH) (Fig. 1h, $0.98 \pm 0.1$ vs. $0.49 \pm 0.2 \mathrm{ng} / \mathrm{mL}, \mathrm{p}<0.05)$ which normally responds to decreased blood levels of IGF-1 [21].

Because we previously reported that, among sepsis patients, non-survivors when compared to survivors had significantly lower blood $1,25(\mathrm{OH})_{2}$ D levels [7], we compared the above measurements between nor-survivors and survivors. Our current data from a different time point of this patient cohort further support the previous finding (Additional file 1: Figure S1 and Table S2, $20.4 \pm 3.4$ vs. $29.7 \pm 1.6 \mathrm{pmol} / \mathrm{L}, \mathrm{p}<0.05)$.

In addition, among the sepsis patients, six patients had chronic kidney disease (Table 2). We therefore asked whether the chronic kidney disease might confound our data analysis because kidney failure impairs its $1 \alpha-$ hydroxylase activity and hence blood $1,25(\mathrm{OH})_{2} \mathrm{D}$ levels [7]. To address this question, we re-analyzed the data by excluding the data from the six patients who had chronic kidney disease. Our data showed that all the observations were similar to what observed when all patients were included (Additional file 1: Figure S2).

Collectively, our data suggest that in sepsis patients multiple disorders negatively affect kidney $1 \alpha$ hydroxylase and hence blood $1,25(\mathrm{OH})_{2} \mathrm{D}$ levels. Such disorders include decreased serum IGF-1 levels, kidney failure as indicated by the increased blood creatinine levels, and increased blood FGF-23 levels. As a result, the suppressed kidney $1 \alpha$-hydroxylase activity cannot be overcome by the increased blood PTH levels. Based on the above observations, we continued to ask whether the suppressed blood $1,25(\mathrm{OH})_{2} \mathrm{D}$ levels correlated with the decreased blood IGF-1 levels and increased blood creatinine levels (kidney failure may directly impair kidney $1 \alpha$-hydroxylase [22] or indirectly via increased blood FGF-23 levels [23]; therefore, blood creatinine levels were used for this analysis). Using Spearman correlation analysis, our data showed that both blood levels of creatinine (Fig. 2a, $\mathrm{R}=-0.333, p=0.006$ ) and IGF-1 (Fig. $2 \mathrm{~b}, \mathrm{R}=$ $0.210, p=0.083)$ moderately correlated with blood 1 , $25(\mathrm{OH})_{2} \mathrm{D}$ levels. These data further support that multiple mechanisms including decreased serum IGF1 levels and kidney failure/increased blood FGF-23 levels contribute to the suppressed blood $1,25(\mathrm{OH})_{2} \mathrm{D}$ levels in sepsis patients.
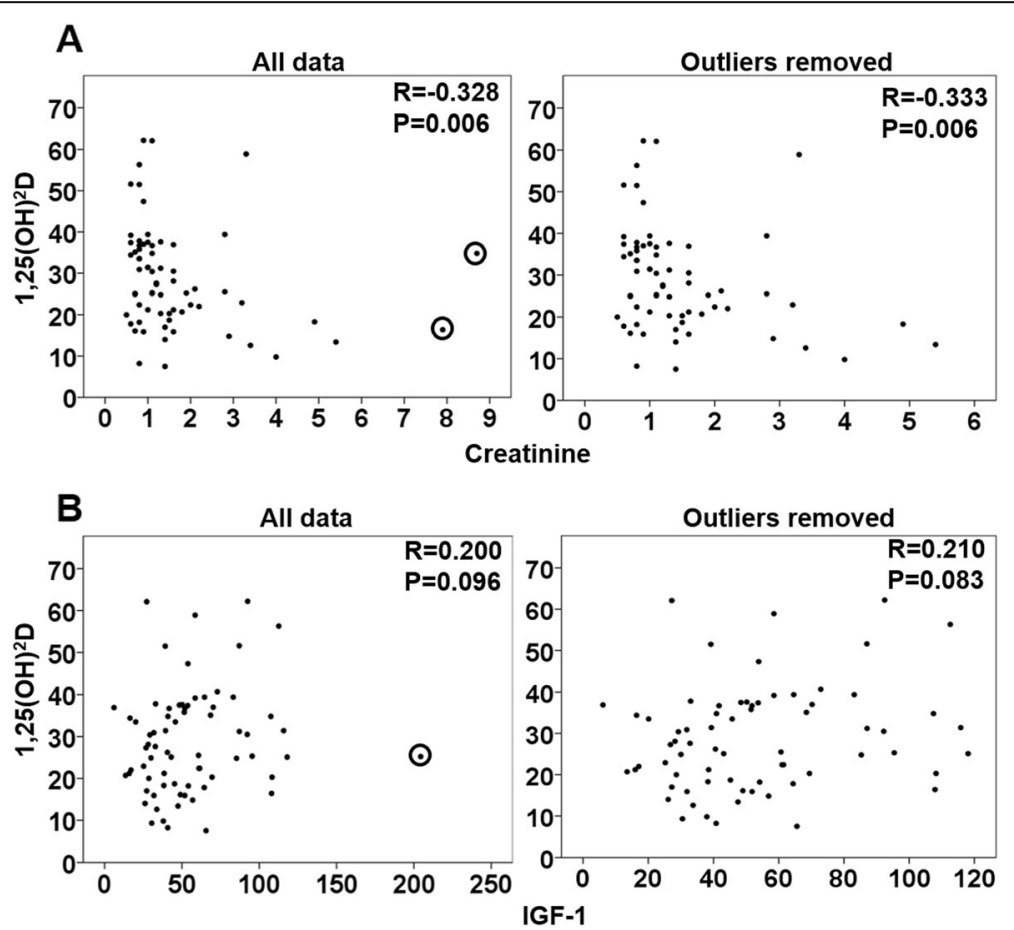

Fig. 2 Increased blood creatinine levels and decreased blood IGF-1 levels correlated with suppressed blood 1,25(OH) 2 D levels in sepsis patients. Correlations of blood 1,25(OH) 2 D levels with blood levels of creatinine (a, left panel) and IGF-1 (b, left panel) in the 79 sepsis patients were analyzed by Spearman correlation analysis. The same analyses were performed after outliers were removed (a, right panel and $\mathbf{b}$, right panel). Circled dots were considered as outliers 
Sepsis mice displayed suppressed blood $1,25(\mathrm{OH})_{2} \mathrm{D}$ levels which were associated with disorders of the mechanisms that regulate 1a-hydroxylase

To further shed light on our discoveries in human sepsis patients, we decided to extend our human study to mice induced for sepsis. Accordingly, C57BL/6 mice were induced for sepsis by cecal ligation and puncture. Twentyfour hours later, sera were collected for analysis. Our data showed that blood IL-6 levels were significantly increased in sepsis mice when compared to healthy control mice [Fig. 3a and Additional file 1: Table S3, 13, $952 \pm 4744 \mathrm{pg} / \mathrm{mL}$ vs. $1.4 \pm 0.0, p<0.05)]$, consistent with ongoing inflammation in the sepsis mice. Additionally, compared to healthy control mice, sepsis mice also displayed significantly decreased blood $1,25(\mathrm{OH})_{2} \mathrm{D}$ levels (Fig. 3b and Additional file 1: Table S3, $55.6 \pm 9.1$ vs. $89.1 \pm 8.5 \mathrm{pmol} / \mathrm{mL}, \mathrm{p}<0.05)$, a finding which was consistent with reduced blood calcium levels (Fig. 3c and Additional file 1: Table S3, $7.2 \pm 0.3$ vs. $9.9 \pm 0.1 \mathrm{mg} / \mathrm{dL}$, $p<0.01)$ that is positively regulated by $1,25(\mathrm{OH})_{2} \mathrm{D}$. Also consistent with the findings in human sepsis patients, sepsis mice showed significantly decreased blood IGF-1 levels (Fig. 3d and Additional file 1: Table S3, $93.2 \pm 7.5$ vs. $449.5 \pm 51.0 \mathrm{ng} / \mathrm{mL}, p<0.01)$ and increased blood creatinine levels (Fig. 3e and Additional file 1: Table S3, $2.3 \pm 0.5$ vs. $0.9 \pm 0.1 \mathrm{mg} / \mathrm{dL}, p<0.05)$. The data suggest that kidney $1 \alpha$-hydroxylase is negatively affected by multiple mechanisms in the sepsis mice, similar to human sepsis patients. Moreover, sepsis mice had increased blood PTH levels (Fig. $3 \mathrm{f}$ and Additional file 1: Table S3, $69.8 \pm 7.6$ vs. $25.7 \pm 1.1 \mathrm{pg} / \mathrm{mL}, p<0.01)$, which was in line with increased blood levels of $3{ }^{\prime}, 5^{\prime}$-cyclic adenosine monophosphate (cAMP) (Fig. 3g, and Additional file 1: Table S3. $22.1 \pm 0.8$ vs. $15.8 \pm 1.1 \mathrm{pmol} / \mathrm{mL}, \quad p<0.01$ ) which reflects PTH activity. Hence, also similar to human sepsis patients, sepsis mice displayed suppressed blood $1,25(\mathrm{OH})_{2} \mathrm{D}$ levels which cannot be overcome by increased blood PTH levels.

\section{Suppression of IGF-1 production in liver during sepsis}

Since the increase in blood FGF-23 levels is known to associate with kidney failure [24], we further investigated the mechanisms leading to the sepsis-induced decrease in blood IGF-1 levels. In this regard, it is known that liver is the major tissue where IGF-1 is produced [25]. Our data showed that, indeed, the mRNA expression of IGF-1 was significantly suppressed in the livers of sepsis mice when compared to healthy control mice (Fig. 4a, 1 \pm 0.4 vs. $2.4 \pm 1.7, \mathrm{p}<0.05)$. Consistent with the suppressed IGF-1 production, blood levels of GH were significantly increased in sepsis mice (Fig. $4 \mathrm{~b}$ and Additional file 1: Tables S3, $22.6 \pm 4.0$ vs. $1.8 \pm 1.0 \mathrm{ng} / \mathrm{mL}$,
A.

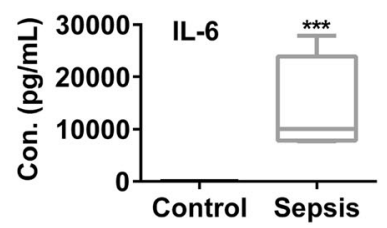

D.

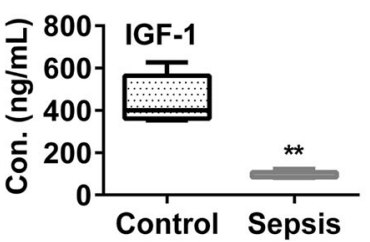

G.

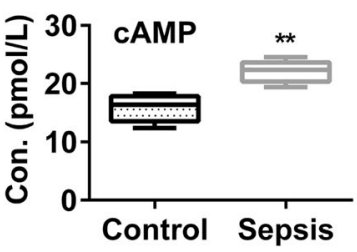

B.

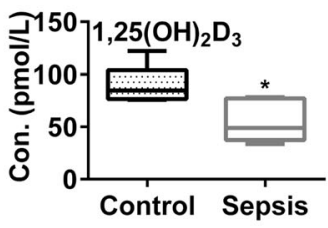

E.

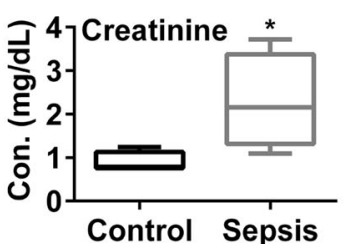

C.

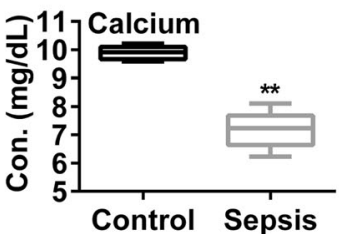

F.

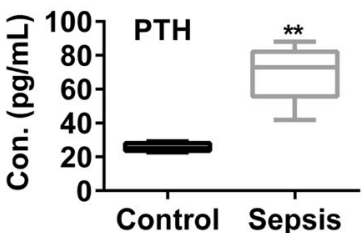

Fig 3 Sepsis mice displayed suppressed blood $1,25(\mathrm{OH})_{2} \mathrm{D}$ levels which were associated with disorders of the mechanisms that regulate 1 ahydroxylase. C57BL/6 mice were induced for sepsis by cecal ligation and puncture. Twenty-four hours later, blood samples were collected and examined for the concentrations of IL-6 (a), 1,25(OH) 2 D (b), calcium (c), IGF-1 (d), creatinine (e), intact PTH (iPTH) (f), and cAMP (g). N = 5. *P $<0.05$. t-test or Mann-Whitney $U$ test 

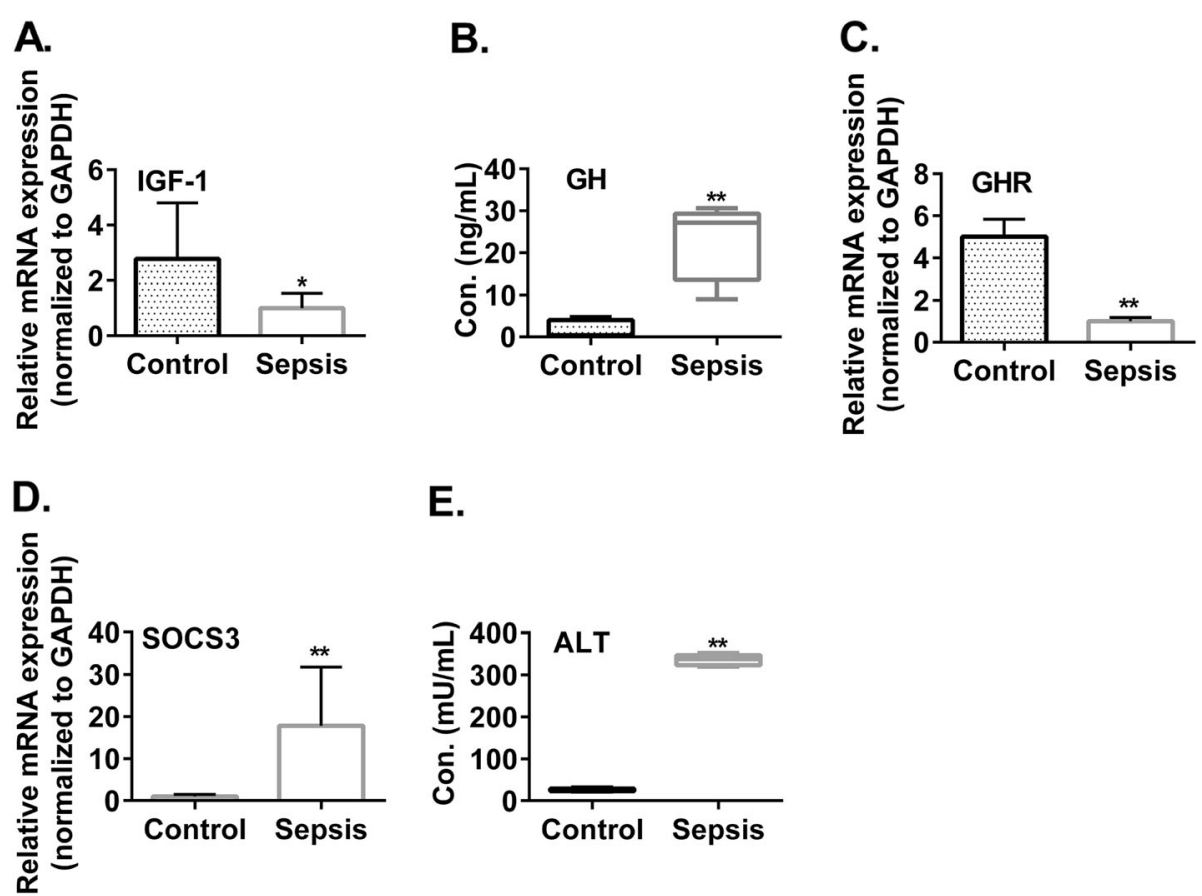

E.

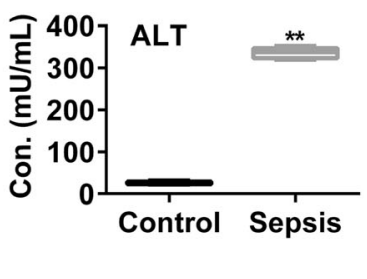

Fig. 4 Suppression of IGF-1 production in liver during sepsis. C57BL/6 mice were induced for sepsis by cecal ligation and puncture. Twenty-four hours later, blood samples and liver tissues were collected. The liver tissues were examined by RT-qPCR for the mRNA expressions of IGF-1 (a), GHR $(\mathbf{c})$, and SOCS3 $(\mathbf{d})$. Additionally, the blood samples were examined for the concentrations of growth hormone $(G H)(\mathbf{b})$ and $A L T(\mathbf{e})$. N =5. ${ }^{*} \mathrm{P}<0.05$. t-test or Mann-Whitney $U$ test

$\mathrm{p}<0.01)$. Therefore, it was evident that the up regulation of GH failed to restore normal production of IGF-1 in sepsis mice, similar to human sepsis patients. We hence studied the pathway that could potentially affect IGF-1 production in liver. Our data showed that the mRNA expression of growth hormone receptor (GHR) was significantly decreased in the livers of sepsis mice when compared to those of healthy control mice (Fig. 4c, $1 \pm$ 0.17 vs. $5.0 \pm 0.8, \mathrm{p}<0.01)$. In addition, the mRNA expression of the suppressor of cytokine signaling 3 (SOCS3), which is a negative regulator of GHR signaling [26], was significantly increased (Fig. $4 \mathrm{~d}, 17.8 \pm 8.5$ vs. $1.0 \pm 0.4, \mathrm{p}<0.01)$. Moreover, we observed increased blood levels of alanine aminotransferase (ALT) in the sepsis mice, indicating liver failure (Fig. $4 \mathrm{e}$ and Additional file 1: Table S3, $334.7 \pm 42.1$ vs. $23.4 \pm 6.2 \mathrm{mU} / \mathrm{mL}, \mathrm{p}<0.01$ ). Collectively, the above data suggest that both suppressed expression and signaling of GHR and liver failure may contribute to the decreased production of IGF-1 in liver.

\section{Discussion}

Our finding of sepsis-induced $1,25(\mathrm{OH})_{2} \mathrm{D}$ deficiency in both human sepsis patients and sepsis mice is clinically significant. Firstly, there is a breakdown of epithelial barrier during sepsis, resulting in local bacterial invasion. In this regard, $1,25(\mathrm{OH})_{2} \mathrm{D}$ stimulates the expression of tight junction proteins and hence protects epithelial barrier [9]. Additionally, this barrier-protection function of $1,25(\mathrm{OH})_{2} \mathrm{D}$ also helps to prevent vascular leakage [10] which is a serious complication in sepsis. Secondly, $1,25(\mathrm{OH})_{2} \mathrm{D}$ stimulates, in immune cells, the production of cathelicidin [11] which acts as an endogenous antimicrobial agent and helps to reduce bacteria burden in sepsis patients. Thirdly, $1,25(\mathrm{OH})_{2} \mathrm{D}$ blocks the production of angiopoietin [12] that plays an important role in the pathogenesis during sepsis. Fourthly, $1,25(\mathrm{OH})_{2} \mathrm{D}$ suppresses inflammation $[9,13]$. However, previous clinical trials of supplementations of native vitamin $\mathrm{D}$ and $1,25(\mathrm{OH})_{2} \mathrm{D}$ did not produce desired outcomes $[14,15]$. For this reason, we reason that the disorders leading to the $1,25(\mathrm{OH})_{2} \mathrm{D}$ deficiency also contribute to mortality among sepsis patients.

Under normal conditions, blood $1,25(\mathrm{OH})_{2} \mathrm{D}$ levels are controlled by multiple mechanisms including genetic factors [27], blood IGF-1 levels [28, 29], blood FGF-23 levels [27], and blood 25(OH)D levels [29]. It has been shown that blood IGF-1 levels positively $[28,29]$ and blood FGF-23 levels negatively [27] correlate with blood $1,25(\mathrm{OH})_{2} \mathrm{D}$ levels. However, blood $25(\mathrm{OH}) \mathrm{D}$ levels do not correlate with blood $1,25(\mathrm{OH})_{2} \mathrm{D}$ levels $[27,30]$. Blood $1,25(\mathrm{OH})_{2} \mathrm{D}$ levels change only when blood 25(OH)D levels change dramatically [30]. In our patient cohort, blood 25(OH)D levels at hospital admission were $21.5 \pm 1.1 \mathrm{ng} / \mathrm{mL}$ [7] which are defined as vitamin D 
insufficiency but not deficiency [31]. Although the potential contribution of decreased blood 25(OH)D levels cannot be excluded, based on the foregoing previous findings, we reason that decreased blood IGF-1 levels and increased blood FGF-23 levels are the major contributors to the suppressed blood $1,25(\mathrm{OH})_{2} \mathrm{D}$ levels.

In our current study, we found that sepsis patients had increased blood FGF-23 levels (Fig. 1e). In addition to negatively regulating kidney $1 \alpha$-hydroxylase activity [23, 32, 33], FGF-23 has other important biological functions because it has been shown that the increase in blood FGF-23 levels is associated with all-cause mortality [34]. A recent open-label randomized trial showed that a FGF-23 blocking antibody (i.e. Burosumab) reduced the severity of rickets in patients with X-linked hypophosphataemia. In this regard, X-linked hypophosphataemia is a monogenetic disease that is characterized by FGF-23 overproduction [35]. However, an intriguing finding was that FGF-23 neutralization, although improving chronic kidney disease-associated hyperparathyroidism, increased mortality in a rat model of chronic kidney disease [36]. Therefore, whether blockage of FGF-23 is beneficial to sepsis patients requires further investigation.

Another important finding in our current study is the decreased blood levels of IGF-1 in sepsis patients (Fig. $1 \mathrm{~g}$ ) and sepsis mice (Fig. 3d). In this regard, in addition to its role in stimulating the activity of kidney $1 \alpha$ hydroxylase [37, 38], IGF-1 can potentially ameliorate kidney and liver failure in sepsis patients [39, 40].
Moreover, IGF-1 has other important biological functions that can be potentially beneficial to sepsis patients, such as suppression of inflammation by enhancing the induction of regulatory $\mathrm{T}$ cells and by decreasing bacterial translocation [41-43]; maintenance of normal gonadal hormone production [44]; protection of mitochondrial function; anti-apoptosis; and protection from vascular leakage [45-47].

Accordingly, the cause of sepsis-induced IGF-1 deficiency is of considerable interest. In this regard, sepsis can cause IGF-I deficiency by disrupting the production of GH or by producing a resistance to the action of $\mathrm{GH}$ to synthesize IGF-I in the liver which is the major source of circulating IGF-I [46]. We found increased blood GH levels in both sepsis patients (Fig. $1 \mathrm{~h}$ ) and sepsis mice (Fig. $4 \mathrm{~b}$ ). This inability of the elevated GH to bring serum IGF-1 to the normal levels suggests a compromised function of GHR in liver. Indeed, this notion is supported by three findings in the livers of sepsis mice. Firstly, it was shown that in sepsis mice the expression of GHR mRNA in liver was significantly suppressed (Fig. 4c). Secondly, the expression of SOCS3 mRNA in liver was significantly increased (Fig. 4d). In this regard, SOCS3 is a negatively regulator of GHR signaling $[26,48]$. We reason that the increased SOCS3 expression in liver is due to proinflammatory cytokines secreted during sepsis (such IL-6 as shown in Fig. 1a and Fig. 3a) because proinflammatory cytokines have been shown to up regulate SOCS3 [26]. Thirdly, there was a liver failure in the sepsis mice (Fig. 4e).

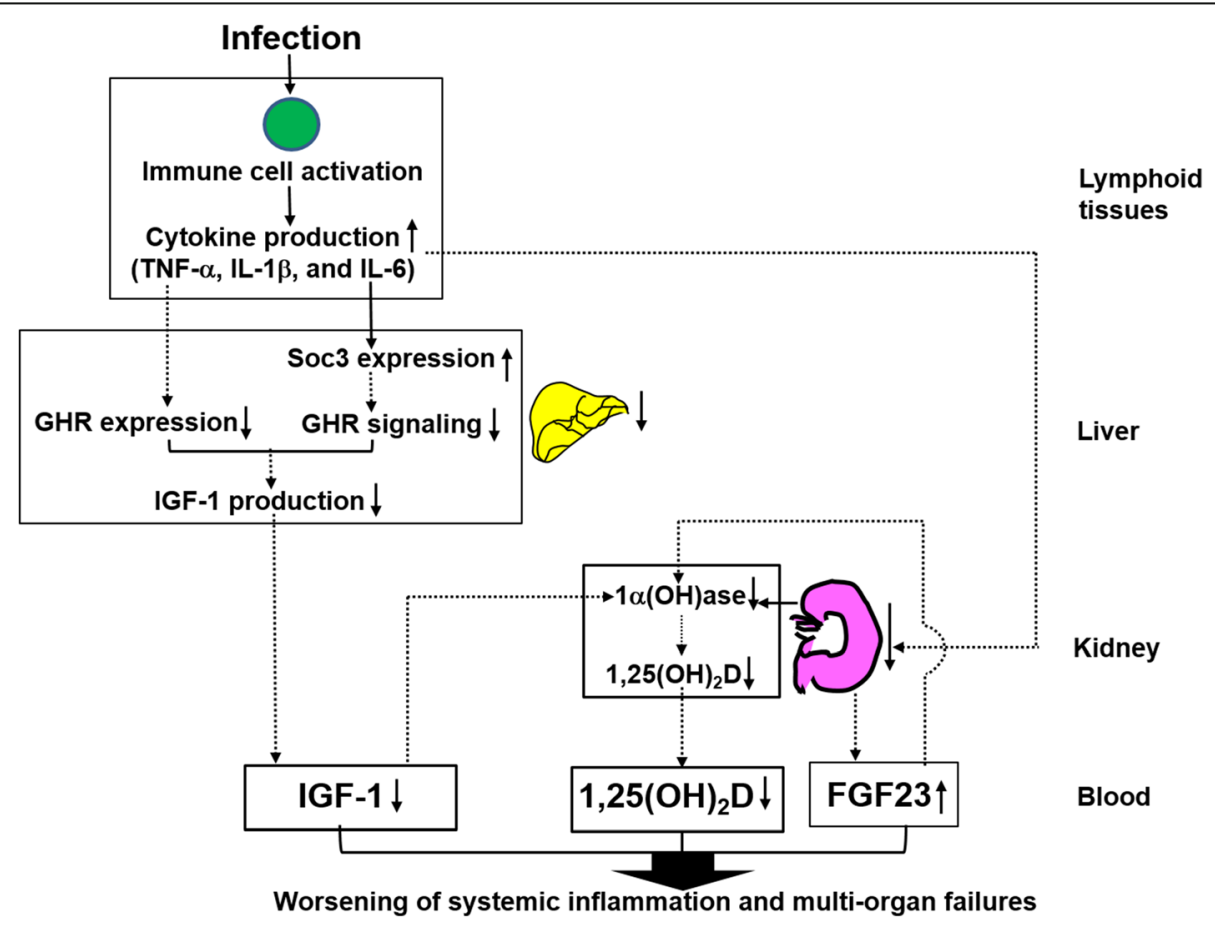

Fig. 5 A model for the mechanisms underlying sepsis-induced $1,25(\mathrm{OH})_{2} \mathrm{D}$ deficiency. See text for description 
Based on our findings, we are proposing a model for the mechanisms underlying sepsis-induced $1,25(\mathrm{OH})_{2} \mathrm{D}$ deficiency (Fig. 5). In the model, an infection leads to activation of immune cells followed by secretion of proinflammatory cytokines, e.g. TNF- $\alpha$, IL-1 $\beta$, and IL-6. These cytokines and liver failure cause inhibition of the expression and signaling of GHR in liver, which leads to reduced production of IGF-1 in liver and decreased IGF-1 levels in blood. In addition, kidney failure increases FGF-23 levels in blood. Consequently, the decreased blood levels of IGF-1, increased blood levels of FGF-23, and kidney failure cause suppressed activity of kidney $1 \alpha$-hydroxylase, leading to reduced production of $1,25(\mathrm{OH})_{2} \mathrm{D}$ in kidney and decreased $1,25(\mathrm{OH})_{2} \mathrm{D}$ levels in blood. Collectively, the increased FGF-23 levels, decreased IGF-1 levels, and decreased 1, $25(\mathrm{OH})_{2} \mathrm{D}$ levels in blood worsen systemic inflammation and multi-organ failures in sepsis patients.

There are several limitations in this study. One is that the blood samples from healthy control subjects were not a part of our previous prospective study. The other limitation is that our study is an association study and not a cause-andeffect result. The third limitation is that, because human creatinine levels measured by the commercial kit all trended high in Fig. 1f, all the data in this figure were divided by 2 from the original data to ensure that creatinine levels in normal healthy control subjects fell into the physiological range. However, this data transformation should not compromise the interpretation in this study because our purpose is to compare normal healthy controls with sepsis patients.

\section{Conclusions}

In this current study, we identified potential mechanisms that lead to the suppressed production of $1,25(\mathrm{OH})_{2} \mathrm{D}$ in sepsis patients. Our study suggests that supplementations of native vitamin $\mathrm{D}$ or $1,25(\mathrm{OH})_{2} \mathrm{D}$ alone may not be sufficient for the treatment of sepsis. Therefore, in order to improve sepsis survival, new therapeutic strategies are needed to target the upstream mechanisms that lead to the suppressed production of $1,25(\mathrm{OH})_{2} \mathrm{D}$. Such upstream mechanisms include decreased production of IGF-1, increased production of FGF-23, and kidney failure.

\section{Supplementary information}

Supplementary information accompanies this paper at https://doi.org/10. 1186/s12879-019-4529-7.

Additional file 1: Table S1. Patient sample measurement results. Table S2. Measurements between survivors and non-sunvivors. Table S3. Mouse sample measurement results. Figure $\mathbf{S} 1$. Blood $1,25(\mathrm{OH})_{2} \mathrm{D}$ levels were significantly lowers in non-survivors when compared to survivors among sepsis patients. Figure S2. Sepsis patients in general displayed suppressed blood $1,25(\mathrm{OH})_{2} \mathrm{D}$ levels which were associated with disorders of the mechanisms that regulate $\mathbf{1} \mathbf{a}$-hydroxylase.

\section{Abbreviations}

1,25(OH) 2 D: 25-dihydroxyvitamin D; 1a-hydroxylase: 25-hydroxyvitamin D 1ahydroxylase; CAMP: 3', 5'-cyclic adenosine monophosphate; FGF-23: Fibroblast growth fact 23; IGF-1: Insulin-like growth factor-1; PTH: Parathyroid hormone

\section{Acknowledgments}

We would like to thank Drs. Yan Xie (University of Redlands, CA) and ChiYing Gao (Chang-Gung Memorial Hospital, Taiwan) for their assistance in statistical analyses of the data presented in this manuscript. We would like to thank Penelope Garcia, Manager - Laboratory Research at Loma Linda University for her technical assistance and preparation of this manuscript.

\section{Authors' contributions}

Study concept and design: DJB, CHL, XT and HBN.; data acquisition, analysis, and interpretation: CHL, XT, DJB, HBN, SW, XW, KHWL, YX, and JZ; drafting of the manuscript: $C H L, X T$, and DJB.; critical revision of the manuscript for important intellectual content: DJB, CHL, XT, KHWL, and HBN; statistical analysis: $\mathrm{CHL}$ and $\mathrm{XT}$.; obtained funding: $\mathrm{DJB}, \mathrm{CHL}$ and $\mathrm{HBN}$.; and study supervision: DJB and XT. All authors read and approved the final version of this manuscript.

\section{Funding}

This study was supported by funds provided by the Department of Medicine at Loma Linda University to DJB and HBN and by the Chang-Gung Memorial Hospital research funding (NO. CMRPG3F2291 and CMRPG3C1431) to CHL. All the funding bodies did not participate in this study.

\section{Availability of data and materials}

Materials are readily available and shall be requested via Dr. Xiaolei Tang (xitang@llu.edu or Xiaolei.tang@liu.edu). Materials will be provided under the material transfer policies of the LLU.

\section{Ethics approval and consent to participate}

This study was approved by the Loma Linda University Institutional Review Board for Human Research (IRB) and Institutional Animal Care and Use Committee (IACUC).

\section{Consent for publication}

$\mathrm{N} / \mathrm{A}$.

\section{Competing interests}

The authors declare that they have no competing interests.

\section{Author details}

'Department of Medicine, Division of Regenerative Medicine, Loma Linda University, Loma Linda, California, USA. 'Department of Emergency Medicine, Chang-Gung Memorial Hospital, Linkou Medical Center, Taoyuan, Taiwan. ${ }^{3}$ Graduate Institute of Clinical Medical Sciences, School of Medicine, Chang-Gung University, Taoyuan, Taiwan. ${ }^{4}$ Department of Veterinary Biomedical Sciences, College of Veterinary Medicine, Long Island University, Brookville, NY 11548, USA. ${ }^{5}$ Division of Infectious Disease, Jinan Infectious Disease Hospital, Shandong University, Jinan, Shandong, China. Institute of Medical and Pharmaceutical Sciences, Zhengzhou University, Zhengzhou, Henan, China. ${ }^{7}$ Musculoskeletal Disease Center, Jerry L. Pettis Memorial Veterans Affairs Medical Center, Loma Linda, California, USA. ${ }^{8}$ Division of Pulmonary, Critical Care, Hyperbaric and Sleep Medicine, Loma Linda University, Loma Linda, California, USA.

Received: 19 June 2019 Accepted: 1 October 2019

Published online: 02 December 2019

\section{References}

1. Kempker JA, Tangpricha V, Ziegler TR, Martin GS. Vitamin D in sepsis: from basic science to clinical impact. Crit Care. 2012;16(4):316.

2. Amrein K, Zajic P, Schnedl C, Waltensdorfer A, Fruhwald S, Holl A, et al. Vitamin $D$ status and its association with season, hospital and sepsis mortality in critical illness. Crit Care. 2014;18(2):R47.

3. Braun A, Chang D, Mahadevappa K, Gibbons FK, Liu Y, Giovannucci E, et al. Association of low serum 25-hydroxyvitamin D levels and mortality in the critically ill. Crit Care Med. 2011;39(4):671-7. 
4. Padhi R, Panda B, Jagati S, Patra SC. Vitamin D status in adult critically ill patients in eastern India: an observational retrospective study. Lung India. 2014;31(3):212-6.

5. Rech MA, Hunsaker T, Rodriguez J. Deficiency in 25-hydroxyvitamin D and 30-day mortality in patients with severe sepsis and septic shock. Am J Crit Care. 2014;23(5):e72-9.

6. Venkatram S, Chilimuri S, Adrish M, Salako A, Patel M, Diaz-Fuentes G. Vitamin D deficiency is associated with mortality in the medical intensive care unit. Crit Care. 2011;15(6):R292.

7. Nguyen HB, Eshete B, Lau KH, Sai A, Villarin M, Baylink D. Serum 1,25dihydroxyvitamin D: an outcome prognosticator in human sepsis. PLoS One. 2013;8(5):e64348.

8. Nair P, Lee P, Reynolds C, Nguyen ND, Myburgh J, Eisman JA, et al. Significant perturbation of vitamin D-parathyroid-calcium axis and adverse clinical outcomes in critically ill patients. Intensive Care Med. 2013;39(2):267-74.

9. Li B, Baylink DJ, Walter MH, Lau KH, Meng X, Wang J, et al. Targeted 25hydroxyvitamin D3 1alpha-hydroxylase adoptive gene therapy ameliorates dss-induced colitis without causing hypercalcemia in mice. Mol Ther. 2015; 23(2):339-51.

10. Zhao H, Zhang H, Wu H, Li H, Liu L, Guo J, et al. Protective role of 1,25(OH)2 vitamin D3 in the mucosal injury and epithelial barrier disruption in DSSinduced acute colitis in mice. BMC Gastroenterol. 2012;12:57.

11. Liu PT, Stenger S, Li H, Wenzel L, Tan BH, Krutzik SR, et al. Toll-like receptor triggering of a vitamin D-mediated human antimicrobial response. Science. 2006;311(5768):1770-3

12. Kong J, Zhu X, Shi Y, Liu T, Chen Y, Bhan I, et al. VDR attenuates acute lung injury by blocking Ang-2-Tie-2 pathway and renin-angiotensin system. Mol Endocrinol. 2013;27(12):2116-25.

13. Li CH, Zhang J, Baylink DJ, Wang X, Goparaju NB, Xu Y, et al. Dendritic cells, engineered to overexpress 25-hydroxyvitamin D 1alpha-hydroxylase and pulsed with a myelin antigen, provide myelin-specific suppression of ongoing experimental allergic encephalomyelitis. FASEB J. 2017;31(7):2996-3006.

14. Amrein K, Schnedl C, Holl A, Riedl R, Christopher KB, Pachler C, et al. Effect of high-dose vitamin D3 on hospital length of stay in critically ill patients with vitamin D deficiency: the VITdAL-ICU randomized clinical trial. JAMA. 2014;312(15):1520-30.

15. Leaf DE, Raed A, Donnino MW, Ginde AA, Waikar SS. Randomized controlled trial of calcitriol in severe sepsis. Am J Respir Crit Care Med. 2014;190(5):533-41.

16. Shapiro NI, Trzeciak S, Hollander JE, Birkhahn R, Otero R, Osborn TM, et al. A prospective, multicenter derivation of a biomarker panel to assess risk of organ dysfunction, shock, and death in emergency department patients with suspected sepsis. Crit Care Med. 2009:37(1):96-104.

17. Calisto KL, Camacho AC, Mittestainer FC, Carvalho BM, Guadagnini D, Carvalheira JB, et al. Diacerhein attenuates the inflammatory response and improves survival in a model of severe sepsis. Crit Care. 2012;16(4):R158.

18. Rittirsch D, Flierl MA, Nadeau BA, Day DE, Huber-Lang M, Mackay CR, et al. Functional roles for C5a receptors in sepsis. Nat Med. 2008;14(5):551-7.

19. Mata-Granados JM, Vargas-Vasserot J, Ferreiro-Vera C, Luque de Castro MD, Pavon RG, Quesada Gomez JM. Evaluation of vitamin D endocrine system (VDES) status and response to treatment of patients in intensive care units (ICUs) using an on-line SPE-LC-MS/MS method. J Steroid Biochem Mol Biol. 2010;121(1-2):452-5.

20. Ghazarian JG, Jefcoate CR, Knutson JC, Orme-Johnson WH, DeLuca HF. Mitochondrial cytochrome p450. A component of chick kidney 25hydrocholecalciferol-1alpha-hydroxylase. J Biol Chem. 1974;249(10):3026-33.

21. Adamek A, Kasprzak A. Insulin-like growth factor (IGF) system in liver diseases. Int J Mol Sci. 2018;19(5):1-24

22. Bosworth $\mathrm{C}$, de Boer $\mathrm{H}$. Impaired vitamin D metabolism in CKD. Semin Nephrol. 2013:33(2):158-68

23. Chanakul A, Zhang MY, Louw A, Armbrecht HJ, Miller WL, Portale AA, et al. FGF-23 regulates CYP27B1 transcription in the kidney and in extra-renal tissues. PLoS One. 2013;8(9):e72816.

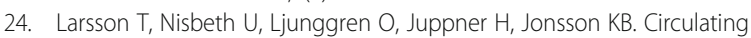
concentration of FGF-23 increases as renal function declines in patients with chronic kidney disease, but does not change in response to variation in phosphate intake in healthy volunteers. Kidney Int. 2003;64(6):2272-9.

25. Ohlsson C, Mohan S, Sjogren K, Tivesten A, Isgaard J, Isaksson O, et al. The role of liver-derived insulin-like growth factor-I. Endocr Rev. 2009;30(5):494-535.

26. Denson LA, Held MA, Menon RK, Frank SJ, Parlow AF, Arnold DL. Interleukin6 inhibits hepatic growth hormone signaling via upregulation of cis and Socs-3. Am J Physiol Gastrointest Liver Physiol. 2003;284(4):G646-54.
27. Fleet JC, Replogle RA, Reyes-Fernandez P, Wang L, Zhang M, Clinkenbeard EL, et al. Gene-by-diet interactions affect serum 1,25-Dihydroxyvitamin D levels in male BXD recombinant inbred mice. Endocrinology. 2016;157(2):470-81.

28. Halhali A, Bourges H, Carrillo A, Garabedian M. Lower circulating insulin-like growth factor I and 1,25-dihydroxyvitamin D levels in preeclampsia. Rev Invest Clin. 1995;47(4):259-66.

29. Trummer C, Schwetz V, Pandis M, Grubler MR, Verheyen N, Gaksch M, et al. Effects of vitamin D supplementation on IGF-1 and calcitriol: a randomizedcontrolled trial. Nutrients. 2017;9(6):1-10.

30. Christensen MH, Lien EA, Hustad S, Almas B. Seasonal and age-related differences in serum 25-hydroxyvitamin D, 1,25-dihydroxyvitamin D and parathyroid hormone in patients from Western Norway. Scand J Clin Lab Invest. 2010;70(4):281-6.

31. Holick MF. The vitamin D deficiency pandemic: approaches for diagnosis, treatment and prevention. Rev Endocr Metab Disord. 2017:18(2):153-65.

32. Bacchetta J, Sea JL, Chun RF, Lisse TS, Wesseling-Perry K, Gales B, et al. Fibroblast growth factor 23 inhibits extrarenal synthesis of 1,25dihydroxyvitamin D in human monocytes. J Bone Miner Res. 2013;28(1):46-55.

33. Shimada T, Hasegawa H, Yamazaki Y, Muto T, Hino R, Takeuchi $Y$, et al. FGF23 is a potent regulator of vitamin D metabolism and phosphate homeostasis. J Bone Miner Res. 2004;19(3):429-35.

34. Vervloet M. Renal and extrarenal effects of fibroblast growth factor 23. Nat Rev Nephrol. 2019;15(2):109-20.

35. Carpenter TO, Whyte MP, Imel EA, Boot AM, Hogler W, Linglart A, et al. Burosumab therapy in children with X-linked hypophosphatemia. N Engl J Med. 2018;378(21):1987-98.

36. Shalhoub V, Shatzen EM, Ward SC, Davis J, Stevens J, Bi V, et al. FGF23 neutralization improves chronic kidney disease-associated hyperparathyroidism yet increases mortality. J Clin Invest. 2012;122(7):2543-53.

37. Kasukawa Y, Baylink DJ, Wergedal JE, Amaar Y, Srivastava AK, Guo R, et al. Lack of insulin-like growth factor I exaggerates the effect of calcium deficiency on bone accretion in mice. Endocrinology. 2003;144(11):4682-9.

38. Adams JS, Ren SY, Arbelle JE, Horiuchi N, Gray RW, Clemens TL, et al. Regulated production and intracrine action of 1,25-dihydroxyvitamin D3 in the chick myelomonocytic cell line HD-11. Endocrinology. 1994;134(6):2567-73.

39. Dichtel LE, Corey KE, Misdraji J, Bredella MA, Schorr M, Osganian SA, et al. The association between IGF-1 levels and the histologic severity of nonalcoholic fatty liver disease. Clin Transl Gastroenterol. 2017;8(1):e217.

40. Bach LA, Hale LJ. Insulin-like growth factors and kidney disease. Am J Kidney Dis. 2015;65(2):327-36.

41. Hunninghake GW, Doerschug KC, Nymon AB, Schmidt GA, Meyerholz DK, Ashare A. Insulin-like growth factor-1 levels contribute to the development of bacterial translocation in sepsis. Am J Respir Crit Care Med. 2010;182(4):517-25.

42. Bilbao D, Luciani L, Johannesson B, Piszczek A, Rosenthal N. Insulin-like growth factor-1 stimulates regulatory $T$ cells and suppresses autoimmune disease. EMBO Mol Med. 2014;6(11):1423-35.

43. Johannesson B, Sattler S, Semenova E, Pastore S, Kennedy-Lydon TM, Sampson RD, et al. Insulin-like growth factor-1 induces regulatory $\mathrm{T}$ cellmediated suppression of allergic contact dermatitis in mice. Dis Model Mech. 2014;7(8):977-85.

44. Mauras N, Rogol AD, Haymond MW, Veldhuis JD. Sex steroids, growth hormone, insulin-like growth factor-1: neuroendocrine and metabolic regulation in puberty. Horm Res. 1996;45(1-2):74-80.

45. Conti E, Carrozza C, Capoluongo E, Volpe M, Crea F, Zuppi C, et al. Insulinlike growth factor-1 as a vascular protective factor. Circulation. 2004;110(15):2260-5.

46. Puche JE, Castilla-Cortazar I. Human conditions of insulin-like growth factor(IGF-I) deficiency. J Transl Med. 2012;10:224.

47. Lyons A, Coleman M, Riis S, Favre C, O'Flanagan CH, Zhdanov AV, et al. Insulinlike growth factor 1 signaling is essential for mitochondrial biogenesis and mitophagy in cancer cells. J Biol Chem. 2017;292(41):16983-98.

48. Flores-Morales A, Greenhalgh CJ, Norstedt G, Rico-Bautista E. Negative regulation of growth hormone receptor signaling. Mol Endocrinol. 2006; 20(2):241-53.

\section{Publisher's Note}

Springer Nature remains neutral with regard to jurisdictional claims in published maps and institutional affiliations. 